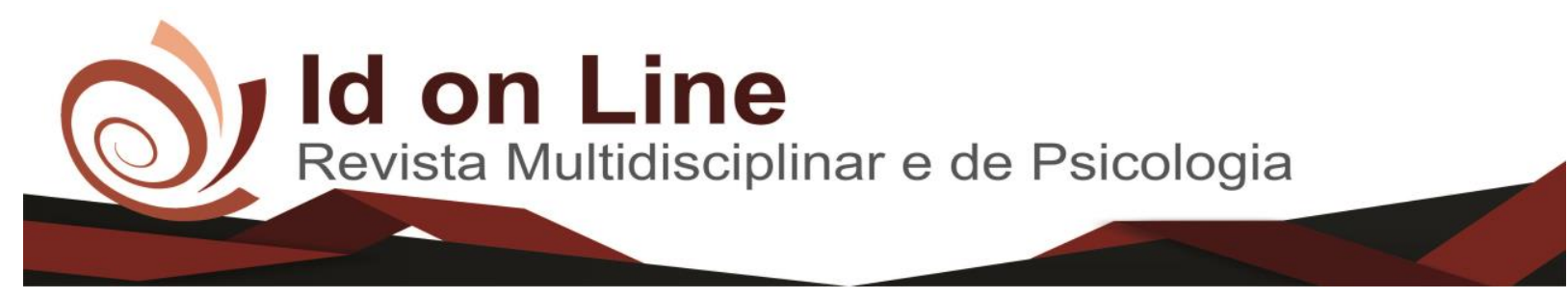

Artigo

\title{
Qualidade da Água Consumida em Escolas Estaduais do Municipio de Vitória da Conquista - BA
}

\author{
Patrícia de Oliveira Menezes ${ }^{\text {; }}$ Larissa Costa Silva Fogaça
}

\begin{abstract}
Resumo: A água é um recurso imprescindível no desenvolvimento de diversas atividades humanas. Apesar de ser uma fonte abundante em nosso planeta, apenas uma pequena parcela é própria para consumo, expondo os indivíduos a inúmeras doenças relacionadas a sua contaminação. Dessa forma objetivou-se com este estudo avaliar os parâmetros físico-químicos e microbiológicos para a caracterização da potabilidade das águas disponíveis nos bebedouros de escolas públicas no município de Vitória da Conquista, Bahia, de acordo com a Portaria $n^{0} 2914$ de 12/12/2011 do Ministério da Saúde, utilizando o pHmetro, para a análise do potencial Hidrogeniônico $(\mathrm{pH})$, o Condutivímetro microprocessado Químis para a análise de sólidos totais dissolvidos (TDS) e condutividade e o Aquatest Coli ${ }^{\circledR}$ (Laborclin), para realizar as análises de Coliformes totais e Escherichia coli. As amostras analisadas neste estudo atenderam aos limites dos parâmetros físico-químicos especificados pela Portaria $\mathrm{n}^{0} 2914$ de 12/12/2011 do Ministério da Saúde. Os resultados demonstraram ausência de coliformes totais e de Escherichia coli em todas as amostras analisadas, estando apropriadas para o consumo.
\end{abstract}

Palavras-chave: Análise microbiológica. Bebedouros. Coliformes totais. Escherichia coli, Parâmetros físicoquímicos.

\section{Quality of Water Consumed in State Schools of The Municipality of Victory of The Conquest - BA}

\begin{abstract}
Water is an essential resource in the development of various human activities. Despite being an abundant source on our planet, only a small portion is fit for consumption, exposing individuals to numerous diseases related to their contamination. The objective of this study was to evaluate the physicochemical and microbiological parameters for the characterization of the potability of the water available in public school drinking fountains in the city of Vitória da Conquista, Bahia, in accordance with Administrative Rule no. 2914 of 12/12 / 2011 by the Ministry of Health, using the pHmeter, for the analysis of the Hydrogenionic potential ( $\mathrm{pH}$ ), the Microprocessed Chemical Conductivity Meter for the analysis of total dissolved solids (TDS) and conductivity and the Aquatest Coli ${ }^{\circledR}$ (Laborclin), to carry out the analysis of Total coliforms and Escherichia coli. The samples analyzed in this study met the limits of the physicochemical parameters specified by Ordinance No. 2914 of 12/12/2011 of the Ministry of Health. The results showed absence of total coliforms and Escherichia coli in all samples analyzed, being appropriate for the consumption.
\end{abstract}

Keywords: Microbiological analysis. Drinking fountains. Total coliforms. Escherichia coli, Physico-chemical parameters.

\footnotetext{
${ }^{1}$ Graduanda em Farmácia pela Faculdade Independente do Nordeste - FAINOR.

E-mail: patriciainterfama@hotmail.com. Vitória da Conquista, Bahia, Brasil.

${ }^{2}$ Orientadora, Professora Ms do Colegiado de Farmácia da Faculdade Independente do Nordeste - FAINOR.

E-mail: larissacosta@fainor.com.br. Vitória da Conquista, Bahia, Brasil.
} 


\section{Introdução}

A água é um recurso imprescindível no desenvolvimento de diversas atividades humanas. Apesar de ser uma fonte abundante em nosso planeta, apenas uma pequena parcela é própria para consumo, além disso, a sua utilização indiscriminada põe-la em risco, tornando-a escassa, com maiores fontes de contaminação ou imprópria ao consumo humano, enfatizando a necessidade urgente de atitudes inteligentes e conscientes (BARROS e AMIM, 2008).

Segundo Mousinho et al. (2014) os usos essenciais da água são: abastecimento doméstico e industrial, irrigação, manejo de animais, preservação da flora e fauna, recreação e lazer, criação de espécies, geração de energia elétrica, navegação. Entretanto, apenas os dois primeiros usos estão comumente interligados a um tratamento prévio da água, por possuírem critérios de qualidades mais contestáveis.

Dessa forma, a agua potável é essencial para garantir a qualidade de vida da população, visto que, por falta da manutenção da exigência de qualidade de água apropriada, os indivíduos ficam expostos a inúmeras doenças relacionadas a sua contaminação e dentre elas pode-se citar: verminoses, cólera, dengue, hepatite, malária, poliomielite (CONFALONIERI e SCHUSTERWALLACE, 2011).

A água potável deve obedecer a padrões de potabilidade preestabelecidos pela legislação. Os parâmetros de qualidade da água são instituídos pela portaria 2914/2011 do Ministério da Saúde, que dispõe sobre os procedimentos de controle e de vigilância da qualidade da água para consumo humano. Esses parâmetros são subsidiados também pela Resolução 357/2005 do CONAMA - Conselho Nacional do Meio Ambiente, que dispõe sobre a classificação dos corpos de água e diretrizes ambientais para seu enquadramento (MENDES et al., 2016).

Os padrões de qualidade para as diversas atividades da água por serem subsidiados legalmente, por meio de legislações que estabeleçam critérios de potabilidade, necessitam ser investigados, com o intuito de garantir condições ideais para seu consumo, minimizando a concentração de microrganismos prejudiciais a saúde. Entre os parâmetros físico-químicos da água que necessitam de avaliação constante estão: o pH, a turbidez, odor, sabor, cor, condutividade elétrica, TDS (teor de sólidos dissolvidos), teor de oxigênio dissolvido na água, temperatura e resistividade elétrica e os parâmetros microbiológicos mais comuns são os 
coliformes fecais, compostos por dois grandes gêneros: os gêneros Escherichia e o Aerobacter (BRASIL, 2013).

Sendo os bebedouros das escolas, a principal fonte empregada para satisfazer a sede dos alunos, o mesmo também pode se tornar uma potencial fonte de contaminação, caso não sejam submetidos a avaliações prévias e contínuas e por comumente encontrarem-se localizados próximos aos banheiros, fonte indireta de contaminação. Na garantia da segurança da ingestão de água saudável, os colégios necessitam se responsabilizar pela realização de fiscalizações e manutenções em cada equipamento e que os mesmos correspondam às normas da Portaria 2914 de 12/12/2011, do Ministério da Saúde (BRASIL, 2017c).

Dessa forma, o presente estudo teve como objetivo avaliar os parâmetros físicoquímicos e microbiológicos para a caracterização da potabilidade das águas disponíveis nos bebedouros de escolas públicas no município de Vitória da Conquista, Bahia, de acordo com a Portaria $n^{0} 2914$ de 12/12/2011 do Ministério da Saúde.

\section{Material e Métodos}

O presente estudo foi conduzido na Faculdade Independente do Nordeste -FAINOR, situada na Avenida Luís Eduardo Magalhães, 1035, Bairro Candeias, na cidade de Vitoria da Conquista. As análises físico-químicas foram realizadas no Laboratório de Química I do Departamento de Laboratórios de Saúde, da própria instituição. As análises microbiológicas foram realizadas no laboratório de Análises de Alimentos e Água, Nutrisegura, situado na Rua 04, n01, Bairro INOCOOP 1 - Candeias, Vitória da Conquista.

\section{Coleta de Amostras}

Os locais definidos para a coleta foram os bebedouros de seis escolas públicas no município de Vitória da Conquista - Bahia, escolhidas de forma aleatória sendo 3 escolas na zona Oeste e 3 na zona leste da cidade, e os responsáveis pela administração destas assinaram uma autorização para obtenção dos dados. Por razões éticas, as escolas públicas estaduais não foram identificadas, sendo decodificadas como escolas. 
A coleta das amostras de água analisadas foi realizada em três dias consecutivos, no período de 09/10 a 11/10, no turno da manhã, para assegurar a repetibilidade do estudo, sendo essas recolhidas preconizando a sua preservação até o momento da análise, conforme determinações do Manual Prático de Análise de Água (Figura 1) (BRASIL, 2013).

Figura 1. Coleta das amostras de água.
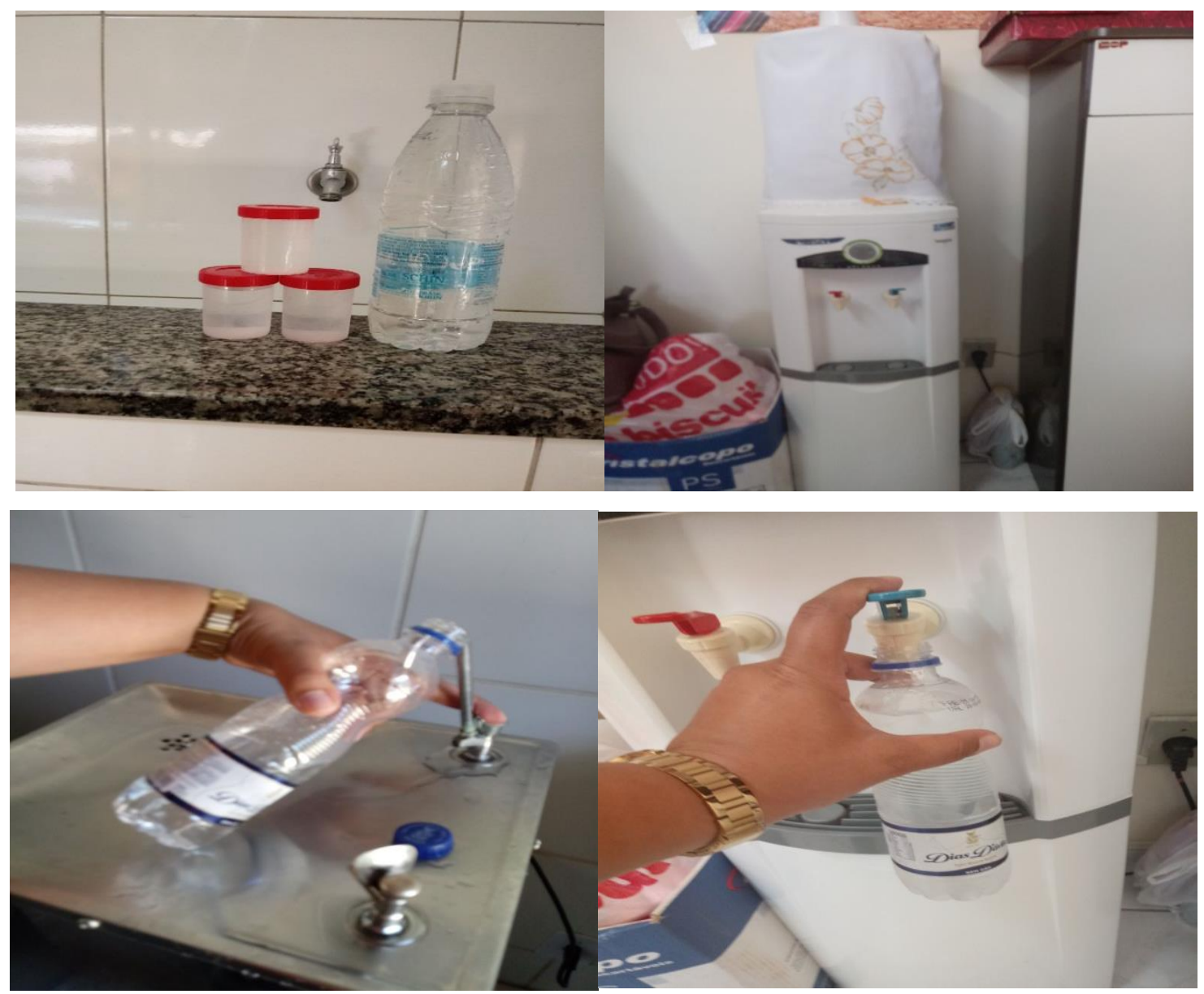

Fonte: Autores da pesquisa (2017).

\section{Análises Físico-químicas}

Dentre os parâmetros físico-químicos, foram determinados o potencial Hidrogeniônico $(\mathrm{pH})$, sólidos totais dissolvidos (TDS) e condutividade. Para a determinação dos parâmetros físico-químicos foram utilizados equipamentos de bancadas digitais, todos previamente calibrados, e as análises realizadas todas em triplicata. Para o potencial Hidrogeniônico $(\mathrm{pH})$ 
utilizou-se pHmetro (Quimis, Q400as). As análises de sólidos totais dissolvidos (TDS) e a condutividade foram determinadas com o auxílio dos equipamentos Condutivímetro microprocessado Químis (Quimis, modelo Cond 250); respectivamente (Figura 2).

Figura 2. PHmetro e Condutivímetro microprocessado Químis, respectivamente.

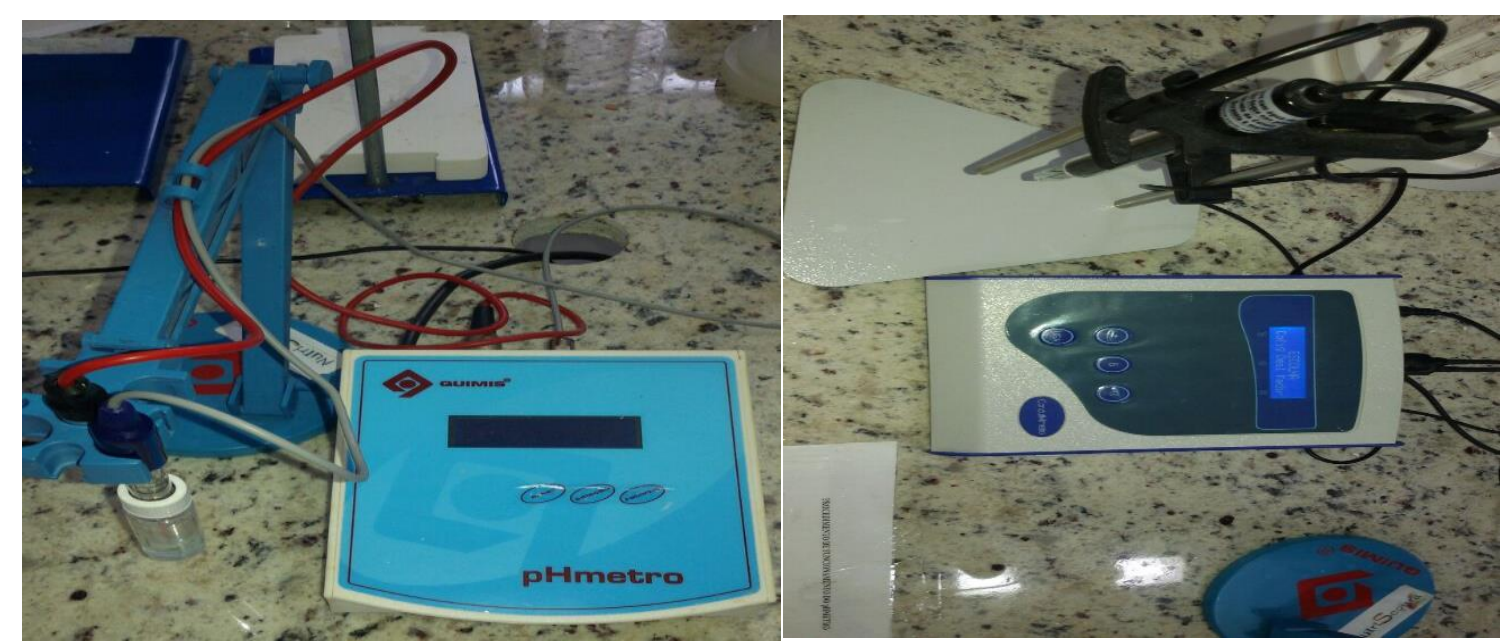

Fonte: Autores da pesquisa (2017).

\section{Análises Microbiológicas}

A confirmação de coliformes totais e Escherichia coli foi realizada através do método simultâneo de avaliação destas, com a utilização do produto Aquateste COLI (Laborclin), de acordo com o Standart Methods for the Examination of Water and a Wastwater, referenciado na Portaria 518/04 do Ministério da Saúde (BRASIL, 2017a). Foram coletadas 3 amostras de $60 \mathrm{~mL}$, em dias alternados nas seis escolas envolvidas no estudo. Para isto, foram utilizados frascos estéreis que foram posteriormente identificados, e encaminhados ao laboratório para realização das análises, conforme recomendações do Manual Prático de Análise de Água (Figura 3) (BRASIL, 2013). 
Figura 3. Análises microbiológicas.

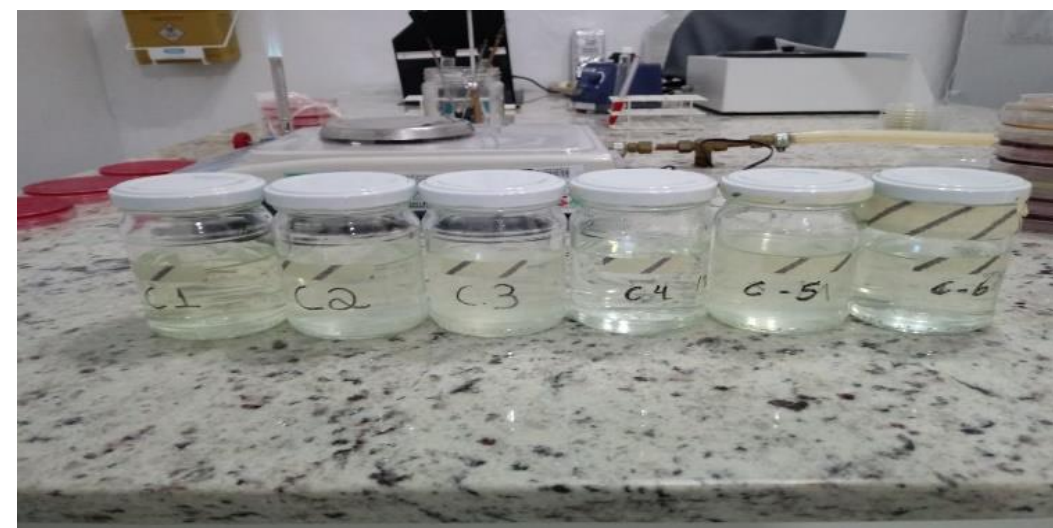

Fonte: Autores da pesquisa (2017).

O teste realizado baseia-se na presença/ausência dos microrganismos patogênicos, com a observação da cor amarela (Figura 4), desenvolvida pelos coliformes que metabolizam os substratos cromogênicos ortonitrofenil- ß-D-galactopiranosideo (ONPG), na presença da enzima $\beta$ - galactosidase, e fluorescência em luz UV, desenvolvida pela Escherichia coli quando esta, metaboliza o substrato 4-metilumbeliferil-ß-D-glucuronide (MUG), na presença da enzima ß-glucuronidase (BEUX et al., 2010).

Figura 4. Verificação de ausência ou presença de coliformes fecais nas amostras.

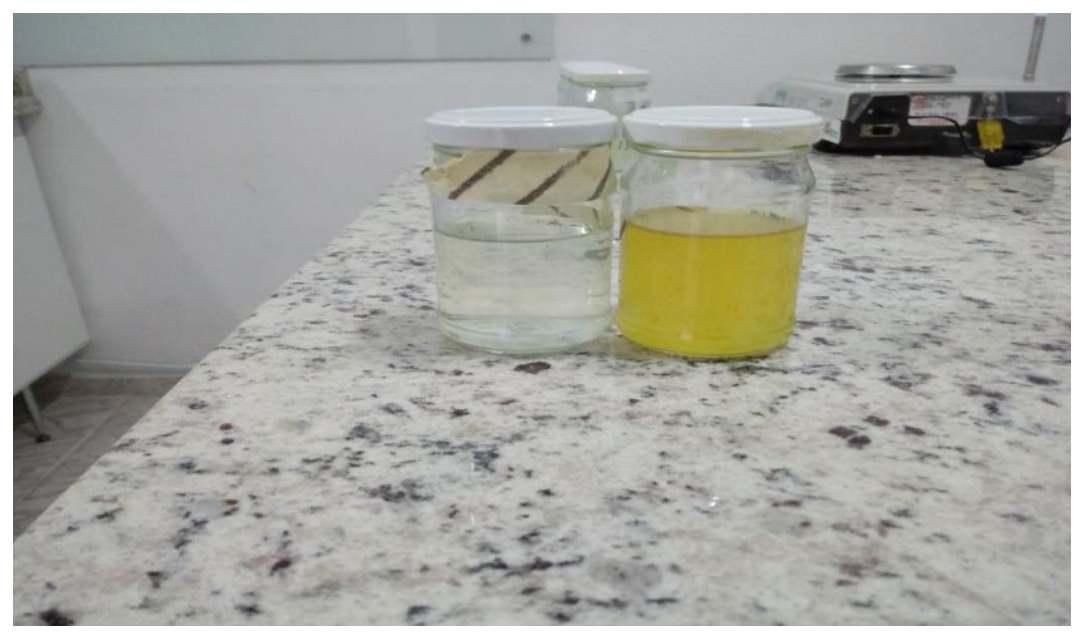

Fonte: Autores da pesquisa (2017). 


\section{Análises Estatísticas}

Todas as determinações físico-químicas e microbiológicas foram efetuadas em triplicata e os resultados foram apresentados como média \pm desvio padrão (DP). O coeficiente de correlação para determinar a relação entre as variáveis foi calculado usando o software Excel.

\section{Resultados e Discussão}

Os resultados das análises físico-químicas foram obtidos pela média das amostras coletadas e realizadas em consonância com os parâmetros físico-químicos estabelecidos pela Portaria $\mathrm{n}^{0} 2914$ de 12/12/2011, conforme o observado na Tabela 1.

Tabela 1: Resultados das amostras em relação a pH, condutividade e teor de sólidos dissolvidos (TDS).

\begin{tabular}{lccc}
\hline $\begin{array}{c}\text { Parâmetros Físicos } \\
\text { químicos }\end{array}$ & $\mathbf{p H}$ & $\begin{array}{c}\text { Condutividade } \\
\left(\boldsymbol{\mu S . c m} \mathbf{- 1}^{-\mathbf{1}}\right)\end{array}$ & $\begin{array}{c}\text { Teor de sólidos } \\
\text { dissolvidos }\left(\mathbf{m g . L} \mathbf{-}^{-\mathbf{1}}\right)\end{array}$ \\
\hline Escola A & $5,48 \pm 1,28$ & $89,25 \pm 1,22$ & $44,31 \pm 1,70$ \\
Escola B & $6,82 \pm 0,25$ & $80,28 \pm 2,24$ & $40,25 \pm 1,18$ \\
Escola C & $6,47 \pm 0,50$ & $83,03 \pm 2,37$ & $41,53 \pm 2,04$ \\
Escola D & $6,82 \pm 0,34$ & $84,87 \pm 3,41$ & $42,47 \pm 1,91$ \\
Escola E & $6,08 \pm 0,31$ & $70,23 \pm 0,70$ & $35,34 \pm 0,43$ \\
Escola F & $6,84 \pm 0,14$ & $79,81 \pm 0,72$ & $40,12 \pm 0,21$ \\
\hline
\end{tabular}

Os resultados encontrados para o pH das águas analisadas variaram entre 5,48 e 6,84, estando a maioria dos valores preconizados na a Portaria $n^{0} 2914$ de 12/12/2011 do Ministério da Saúde (BRASIL, 2017c), exceto a Escola A que apresentou um valor inferior aos limites estabelecidos pela Portaria. Valores acima ou abaixo destes parâmetros de potencial hidrogeniônico da água podem ser um agravante, principalmente se esta é destinada ao consumo humano, podendo acarretar em irritações na pele e olhos. Discrepâncias nestes valores são 
inviáveis também para as redes de abastecimento podendo causar corrosões ou incrustações nas tubulações (MOURA, et al., 2013).

Mendes et al. (2016), avaliando a qualidade da água de bebedouros da Universidade do Estado do Pará (UEPA) observou que algumas amostras obtiveram valores abaixo do intervalo estabelecido pela legislação brasileira, variando entre 3,92 e 7,64, valores estes inferiores aos encontrados neste estudo.

A Portaria do Ministério da Saúde n 2.914/2011 preconiza que o limite máximo de sólidos solúveis seja de $1000 \mathrm{mg}$. L ${ }^{-1}$ (BRASIL, 2017c), entretanto as amostras coletadas apresentaram valores baixos de TDS se comparado ao padrão determinado pela Portaria, com resultados entre 35,34 e 44,31 mg.L $\mathrm{L}^{-1}$, considerando-se que os sólidos dissolvidos possuem uma dimensão inferior a $10^{-3} \mu \mathrm{m}$, constituídos por sais minerais e matéria orgânica dissolvida (VON SPERLING, 2005). Esses resultados estão em consonância com os resultados obtidos por Castro et al. (2013) na qual todas as amostras estudadas de água potável dos bebedouros de uma instituição de ensino, encontravam-se dentro do permitido para consumo.

A condutividade na avaliação de amostras de água para consumo pode identificar o eventual lançamento de efluentes na rede e uma deficiência no tratamento dessas, por relacionar-se à concentração de sólidos dissolvidos (Maciel, et al., 2016). Apesar dos valores padrões de referência da condutividade elétrica não estarem descritos na resolução do Conselho Nacional do Meio Ambiente (Conama) 357/2005 (BRASIL, 2017b), ele pode ser utilizado para complementar os estudos dos sólidos totais dissolvidos, por ser diretamente proporcional aos valores dessa variável (MORAIS, et al., 2016). Isto pode ser verificado conforme os resultados

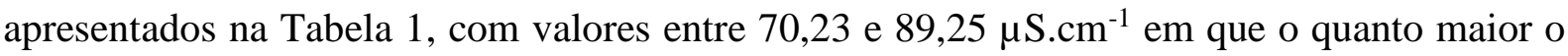
teor de sólidos totais, maior a sua condutividade. Morais et al., (2016), observou que a condutividade era diretamente proporcional ao teor de sólidos solúveis, confirmando a correlação entre estes parâmetros.

Os resultados obtidos da qualidade microbiológica das amostras em estudo, relativos às determinações de Coliformes Totais e Echerichia Coli, estão apresentados na Tabela 2. 
Tabela 2: Resultados das amostras em relação a resultados microbiológicos.

\begin{tabular}{lll}
\multicolumn{1}{c}{$\begin{array}{c}\text { Parâmetros } \\
\text { microbiológicos }\end{array}$} & Coliformes Totais & E.Coly \\
\hline Escola A & Ausência & Ausência \\
Escola B & Ausência & Ausência \\
Escola C & Ausência & Ausência \\
Escola D & Ausência & Ausência \\
Escola E & Ausência & Ausência \\
Escola F & Ausência & Ausência \\
\hline
\end{tabular}

A Portaria $n^{\circ}$ 2914/2011 do Ministério da Saúde relata que amostras destinadas ao consumo humano não podem apresentar coliformes totais e E. coli (BRASIL, 2017c). Observase que em todos os pontos de coletas os resultados foram negativos para a presença de ambos, estando dentro do padrão microbiológico da água para consumo humano e de acordo com a legislação vigente, corroborando com os resultados encontrados por Castro et al. (2013), não detectando a presença de coliformes totais nem de E. coli.

A ausência da bactéria Gram negativa E. coli evidencia a qualidade bacteriológica satisfatória da água dos bebedouros destinados ao consumo, visto que essa bactéria é normalmente encontrada no trato gastrointestinal de mamíferos e sua ausência nas amostras representa um indicativo que esta não está contaminada por material fecal. As cepas de $E$. coli não apresenta patogenicidade, mas podem ser responsáveis por doenças gastrointestinais por meio de graves intoxicações intestinais (MORAIS, et al., 2016).

\section{Conclusão}

As amostras analisadas neste estudo atenderam aos limites dos parâmetros físicoquímicos especificados pela Portaria $n^{0} 2914$ de 12/12/2011 do Ministério da Saúde. Os resultados demonstraram também a ausência de coliformes totais e de Escherichia coli em todas as amostras analisadas, estando apropriadas para o consumo. 
A obtenção dos processos de higienização obtidos pelas instituições de ensino quanto à assepsia dos bebedouros e de filtros que existem neles torna-se uma rotina de suma importância para diminuir os níveis de contaminação da água. Sendo assim, as amostras de água dos bebedouros de todas as Instituições de ensino, encontram-se próprias para consumo humano, em conformidade com os padrões estabelecidos pelo Ministério da Saúde e CONAMA. É importante a análise dos parâmetros de qualidade das águas dos bebedouros constantemente, uma vez que estes atendem um grande público. Estas análises são importantes para a comunidade consumidora pois alerta sobre a qualidade do produto oferecido.

\section{Referências}

BEUX, M. R. et al. Análise Comparativa entre o Método do Substrato Cromogênico "Aquateste Coli" e o Método de Fermentação da Lactose na Pesquisa de Coliformes em Água de Consumo Humano. In: INTERNACIONAL CONGRESS ON BIOPROCESS IN FOOD INDUSTRIES, 4., 2010. Curitiba. Anais...Curitiba: sbCTA, 2010.

BRASIL. FUNDAÇÃO NACIONAL DE SAÚDE. Manual prático de análise de água / Fundação Nacional de Saúde - 4. ed. - Brasília: Funasa, 150 p, 2013.

BRASIL. Ministério da Saúde. Portaria 518 de 25 de Março de 2004. Disponível em: < http://www.aeap.org.br/doc/portaria_518_de_25_de_marco_2004.pdf >. Acesso em 11 de outubro de 2017a.

BRASIL. CONAMA - Conselho Nacional do Meio Ambiente. Resolução n $\mathbf{n}^{\mathbf{0}}$ 357, de 17 de Março de 2005. Disponível em: http://www.mma.gov.br/port/conama/legiabre.cfm?codlegi=459 >. Acesso em 25 de outubro de 2017b.

BRASIL. Ministério da Saúde. Portaria No 2.914, De 12 de Dezembro de 2011. Disponível em: < http://portalarquivos.saude.gov.br/images/pdf/2015/maio/25/Portaria-MS-no-2.914-1212-2011.pdf >. Acesso em 11 de outubro de 2017c.

CASTRO, A.D.S.; SILVA, B.M. da; FABRI, R.L. Avaliação da qualidade físico-química e microbiológica da água dos bebedouros de uma instituição de ensino superior de Juiz de Fora, Minas Gerais. Nutrir Gerais, Ipatinga, v. 7 n. 12, p. 984-998, fev./Jul. 2013.

CONFALONIERI, U.E.C.; SCHUSTER-WALLACE, C.J. Data integration at the water-health nexus. Current Opinion in Environmental Sustainability.v. 3, p. 512-516, 2011. 
MACIEL, A.; DRESCHER, c. ғ.; PEIXOTO, s. c. Avaliação da qualidade da água do rio Jacuí e divulgação dos resultados na comunidade escolar. Disciplinarum Scientia. Série: Naturais e Tecnológicas, Santa Maria, v. 16, n. 1, p. 433-444, 2016.

MENDES, M.P.; SILVA, N.S.G.; CARVALHO, J.R.C.; JÚNIOR, J.B.P.; DINIZ, V.W.B. Avaliação da qualidade da água dos bebedouros da Universidade do Estado do Pará na cidade de Belém Pará, Brasil. Scientia Plena, v. 12, n. 6, 2016.

MOUSINHO, D. D.; DE SOUSA GONÇALVES, L.; SARAIVA, A.; DE CARVALHO, R. M. Avaliação da qualidade físico-química e microbiológica da água de bebedouros de uma creche em Teresina-PI. Revista Interdisciplinar, v.7, n.1, 93-100, 2014.

MORAIS, W. A.; SALEH, B. B.; ALVES, W. S.; AQUINO, D. S. Qualidade sanitária da água distribuída para abastecimento público em Rio Verde, Goiás, Brasil. Caderno de Saúde Coletiva, v. 24, n. 3, 361-367, 2016.

VON SPERLING M. Introdução à qualidade das águas e ao tratamento de esgotos. 3 ed. Belo Horizonte: Editora UFMG. 452 p, 2005.

Como citar este artigo (Formato ABNT):

MENEZES, Patrícia de O.; FOGAÇA, Larissa C. S. Qualidade da Água Consumida em Escolas Estaduais do Municipio de Vitória da Conquista - BA.. Id on Line Revista Multidisciplinar e de Psicologia, 2017, vol.11, n.38, p.612-622. ISSN: 1981-1179.

Recebido: 01.10.2017

Aceito: 03.11.2017 